\title{
Alcohol use in opioid agonist treatment
}

Seonaid Nolan ${ }^{1,2^{*}}$, Jan Klimas ${ }^{1,3}$ and Evan Wood ${ }^{1,2}$

\begin{abstract}
Alcohol misuse among individuals receiving agonist treatment for an opioid use disorder is common and is associated with significant morbidity and mortality. At present, though substantial research highlights effective strategies for the screening, diagnosis and management of an alcohol or opioid use disorder individually, less is known about how best to care for those with a dual diagnosis especially since common treatments for opioid addiction may be contraindicated in a setting of alcohol use. This review summarizes existing research and characterizes the prevalence, clinical implications and management of alcohol misuse among individuals with opioid addiction. Furthermore, it highlights clinically relevant management strategies in need of future research to advance care for this unique, but important, patient population.
\end{abstract}

Keywords: Alcohol use, Alcohol misuse, Alcohol use disorder, Opioid agonist treatment, Methadone, Buprenorphine/ naloxone

\section{Background}

Approximately one-third of individuals who receive opioid agonist treatment (OAT), such as methadone or buprenorphine/naloxone for the management of an opioid use disorder, also misuse alcohol [1]. Despite alcohol use being a risk factor for fatal overdose among individuals prescribed opioids, as well as being an established risk factor for addiction treatment non-compliance among OAT participants [2-4], little guidance currently exists outlining effective management strategies for this patient population. Consequently, an individual's alcohol misuse frequently goes undiagnosed and untreated [5-7]. The potential risk for relapse to opioid use, as a result of this missed opportunity, as well as the host of negative consequences that can occur from this or from untreated alcohol misuse is significant among this patient population [8-15]. This review summarizes the existing research of alcohol misuse among OAT participants with a specific focus on prevalence, clinical implications and management. Clinically relevant management strategies in need of future research are additionally highlighted to advance care for this unique, but important, patient population.

\section{Methods \\ Search strategy}

This narrative review was based on a literature search using Pubmed and Ovid Medline databases. Keywords used described unhealthy patterns of alcohol use and included: alcohol, alcohol addiction, alcohol misuse, harmful alcohol use, hazardous alcohol use, heavy alcohol use, alcohol abuse, alcohol dependence or alcohol use disorder. These terms were combined with terms referring to OAT including: opioid addiction treatment, OAT, buprenorphine or methadone. Studies written in English were included. Additionally, references for all studies identified through the database search were examined to identify articles that may have been missed. Articles focused on prevalence, clinical implications, screening or management of alcohol misuse among OAT participants were reviewed in detail and are summarized.

\section{Prevalence}

Estimating the prevalence of alcohol misuse among opioid dependent individuals receiving OAT is challenging. Substantial variation exists within the literature among patient populations and treatment settings being

\footnotetext{
*Correspondence: seonaidn@gmail.com

1 British Columbia Centre for Excellence in HIV/AIDS, St. Paul's Hospital, 608-1081 Burrard Street, Vancouver, BC V6Z 1Y6, Canada

Full list of author information is available at the end of the article
} 
studied. Furthermore a lack of standardization pertaining to alcohol misuse terminology and measurement of this is common. In this review, 'alcohol misuse' is defined as the consumption of alcohol in a quantity that exceeds low risk for developing an alcohol use disorder as defined by the National Institute on Alcohol Abuse and Alcoholism (i.e. no more than 3 drinks in a single day and no more than 7 drinks per week for women and no more than 4 drinks in a single day and no more than 14 drinks per week for men) and includes both people with 'risky drinking,' 'alcohol abuse or dependence' and those with an established 'alcohol use disorder' [16].

A 2015 review by Soyka et al., estimated one-third of methadone maintenance participants also have problematic alcohol use [1]. Other studies are in agreement with this estimate including a meta-analyses of U.S. clinical trials which demonstrated $38 \%$ of individuals seeking treatment for opioid use to have a concurrent alcohol use disorder, as defined by a diagnosis of either alcohol abuse or dependence using criteria from the Diagnostic and Statistical Manual of Mental Disorders (DSM-IV) [9]. Beyond the U.S., data from the British National Treatment Outcome Research Study, a large prospective study of drug users, indicates that at the time of enrolment in a community methadone clinic just over one-third of clients were drinking alcohol above the recommended limits with no statistically significant change observed after 1 year of follow-up [5]. Lastly, a cross-sectional study of current or former heroin users attending primary care for methadone maintenance treatment in Ireland revealed the prevalence of problem alcohol use [as defined by an Alcohol Use Disorder Identification Test (AUDIT) score of $>7$ ] to be $35 \%$ [17]. Collectively, these data suggest that approximately one-third of opioid addicted individuals in treatment may have concurrent alcohol misuse.

\section{Interactions}

While interactions between alcohol and opioids have previously been described $[1,18]$, research focused specifically on alcohol in the context of OAT is scarce [19]. Animal studies involving methadone predominate and repeatedly demonstrate an influence of ethanol on methadone metabolism and vice versa [19]. More specifically, among rat subjects, acute ethanol consumption increased peak methadone concentration $[20,21]$ while chronic ethanol use led to a reduction in peak methadone levels [21-23]. Similarly, acute methadone administration has been shown to decrease the rate of ethanol metabolism (and thus increase blood alcohol levels) [20] whereas chronic methadone use leads to a reduction in blood alcohol levels [24, 25]. Human research focused on this issue is scarce [19]. Clinical observations among individuals who receive methadone maintenance therapy report less of an effect of alcohol [23,26], more sedation at the time of peak methadone levels as well as more rapid dissipation of methadone's overall effect resulting in opioid withdrawal symptoms [23]. One study by Lenne et al. [27] did demonstrate a small but significant effect of increased blood alcohol concentration (BAC) among non-opioid study controls compared to those receiving regular OAT. A subsequent study by Clark et al. [19] furthered these findings by demonstrating the interaction between alcohol and opioids to be strongest at the time of peak plasma levels after opioid dosing (i.e. a dose-response relationship) as well as reporting an opioid-specific difference in the magnitude of this interaction (e.g. methadone versus buprenorphine). While these findings support the case for a true pharmacokinetic interaction among humans between alcohol and opioids, the specific site(s) of such interaction requires further study. Furthermore, it should be emphasized that the overall magnitude of the reduction of BAC among individuals receiving OAT in these studies is small (and likely of limited clinical significance) and individuals who receive OAT and consume alcohol will still experience a greater opioid effect due to the combined sedative effect of both substances [19].

\section{Clinical implications}

Knowledge of the potential mechanisms of interaction between OAT and alcohol and their effect on blood levels is of importance, but equally so is determining the clinical significance of these mechanisms.

\section{Effect of OAT initiation on alcohol consumption}

To date, studies investigating the effect of OAT initiation on alcohol consumption among individuals with alcohol misuse and an opioid use disorder are mixed. For example, Caputo et al. [28] demonstrated short term methadone treatment to be associated with a reduction in alcohol levels while long term methadone maintenance therapy resulted in increased alcohol consumption. While an inverse relationship between heroin use and alcohol use has previously been described [29,30], a recent study found methadone enrolment to have no effect on heavy drinking and may even appear to decrease the initiation of heavy drinking among heroin users [31]. Furthermore, a 12-month longitudinal study of individuals with both heroin addiction and alcohol dependence demonstrated both methadone and buprenorphine to be associated with a reduction in alcohol use, with buprenorphine being more efficacious [32]. Lastly, a recent meta-analyses involving 15 studies showed no clear pattern regarding the effects of OAT on alcohol consumption with 3 studies indicating an increase in alcohol consumption during treatment, 3 studies indicating a decrease in alcohol consumption and 9 studies reporting no change [33]. 


\section{Overdose and mortality}

Alcohol use has previously been identified to be a risk factor for increased overdose and mortality among individuals receiving OAT [34, 35]. The degree of increased risk conferred overall and according to alcohol consumption patterns however (i.e. hazardous or harmful use compared to an alcohol use disorder) is currently lacking. A cross-sectional study by Zador et al. examined the number and causes of death among participants of a methadone maintenance treatment program in Australia and demonstrated drug-related death to account for the highest proportion of mortality (44\%), with alcohol use being cited as the third most common substance of use after benzodiazepines and other opioids [34]. Similarly, a New-York based longitudinal follow-up study of active and discharged methadone patients reported excessive alcohol use ( $\geq 4$ oz per day for a 3 month period) to be the leading cause of death among active methadone participants (35\%) and the second most common cause of death, following complications with opiates, among discharged methadone patients (39\%) [35].

Mechanisms driving this process are likely diverse (e.g. suicide attempts, unintentional overdoses involving various substances including benzodiazepines, illicit opioids and OAT, etc.) and not well described, but likely relate to the interactions between alcohol and methadone outlined previously. As such, individuals should routinely be advised of the compounded risk of acute and chronic alcohol consumption while in receipt of OAT and, in particular, of the risk of relapse to illicit opioid use. In addition, during methadone initiation, a period already known to be associated with an increased risk for overdose and mortality [34, 36], concurrent acute ethanol consumption can further compound this risk by increasing CNS and/or respiratory depression [37, 38]. Similarly, though methadone maintenance treatment may lead to lower blood alcohol levels after consumption compared to non-methadone users, one's overall risk for overdose and mortality is still increased given the combined sedative effect of both methadone and alcohol [26].

\section{Other clinical outcomes}

Beyond increasing one's risk for overdose and mortality, alcohol misuse among individuals concurrently receiving OAT has been associated with a host of other negative clinical outcomes. Specific to addiction treatment, alcohol misuse has been shown to be risk factor for poor compliance with pharmacotherapy [9] and a predictor for negative treatment outcomes [2-4]. As such, individuals with ongoing alcohol misuse are at an increased risk for a relapse to opioids or other substances [9]. Furthermore, as hepatitis infection is a common comorbidity among opioid dependent individuals with prevalence estimates ranging from 64 to $100 \%$ in some cohorts [39-44], chronic alcohol misuse can result in hepatotoxicity and increase an individual's risk for progression to cirrhosis $[11,13,15]$. Additionally, alcohol misuse can exacerbate psychiatric comorbidities such as anxiety, depression and suicidality, all of which are known to be more common among OAT recipients [8, 10, 12, 45, 46]. Lastly, a study by Sebanjo et al. demonstrated alcohol misuse to be associated with a significant reduction in quality of life and social functioning among methadone maintained individuals [14].

\section{Screening}

Annual screening and brief intervention for alcohol misuse among OAT participants is recommended by clinical guidelines given both its prevalence and potential for a myriad of negative consequences. While the effectiveness of such practices among general populations has shown mixed results [47-49], a significant reduction in alcohol consumption has been observed among methadone maintenance participants in several trials including part of a systematic review [50-54]. More specifically, these studies included participants of both community and designated methadone maintenance clinics in both a European [50, 53] and U.S. [51] setting with the intervention being delivered by either a clinician [50], nurse [51, 53] or trained therapist [51]. Despite this finding, implementation of these interventions among primary care providers of OAT has been slow [55] and remains variable with rates ranging between 2 and 93\% [56, 57]. Furthermore, when screening does occur in these settings it is often completed without the use of a validated screening tool $[7,58]$. Suggested reasons for these findings identify time restrictions, lack of resources and physician attitudes about the effectiveness of screening and brief intervention for the detection and management of alcohol misuse [52].

Creation of a guideline for alcohol misuse screening and treatment specific for OAT participants has previously been described as a potential solution to mitigate these challenges [59]. Reasons for such a document include: (1) the high prevalence of alcohol misuse among OAT participants, suggesting the need for a more proactive and systematic approach to screening and treatment; (2) consideration for the use of lower thresholds to not only define alcohol misuse but also guide timing for referral to treatment; and (3) the need for involvement of an addiction specialist for severe cases of recurrent or persistent alcohol misuse among this patient population.

While no such dedicated guideline exists in the U.S., a recent clinical guideline was published in Europe and addressed problem alcohol use among substance users who attended primary care (the vast majority for OAT) 
in Ireland [59]. Screening recommendations from this guideline suggest random, but at least annual, screening for alcohol misuse using AUDIT C (a 3-item version of the Alcohol Use Disorder Identification Test) as an initial screening instrument, with a positive result requiring administration of the full AUDIT. While other diagnostic screening tools (e.g. blood or urine tests, breathalyzer) can be incorporated into the screening process, their utility is limited and should be reserved to either provide pertinent information to a treating physician or help motivate a patient to address their alcohol misuse. A positive screening test for alcohol misuse should be followed up with screening for other substance use and medical comorbidities including hepatitis and other chronic diseases (e.g. cardiac, liver).

\section{Management}

Despite one-third of OAT participants misusing alcohol, treatment for this has widely been ignored [1]. One New York study demonstrated $21 \%$ of methadone maintenance patients to misuse alcohol with only $5 \%$ being enrolled in outpatient alcohol detox and 7\% engaging in psychosocial intervention [6]. A more recent 12-month follow up study among people who use drugs demonstrated little improvement in patterns of drinking among the majority of participants [5]. These findings may be explained by the limited access to alcohol treatment programs that exists for this patient population given many such programs require termination of a patient's OAT use as a condition of acceptance $[6,60]$. To date, though a theoretical risk for over sedation or overdose may exist among OAT participants being treated for alcohol withdrawal, no research to date has clearly quantified the magnitude of this risk or demonstrated any clear interaction between sedative medications used during alcohol detoxification or treatment (e.g. benzodiazepines, barbiturates) and OAT regarding these specific outcomes (though a precipitated opioid withdrawal syndrome has previously been reported with concurrent methadone and phenobarbital administration) [61]. This may relate to the use of these medications within a therapeutic dose range and their administration, which often occurs in a supervised setting. As such, at the present time, no justifiable clinical reason exists to deny entry for treatment of alcohol misuse to an individual that is well established on an OAT program or the need for any modification in dose. Doing so may only increase one's risk for opioid relapse and the host of negative medical and psychosocial consequences as described above.

Based on the above, all OAT participants identified as having alcohol misuse should be offered treatment. In the acute period, management of alcohol withdrawal in an effective and safe manner is the most important consideration. Unfortunately strategies on how best to accomplish this are lacking in the literature and warrant further study. Validation of risk scoring tools like the Prediction of Alcohol Withdrawal Severity Scale (PAWSS) among this patient population may be of benefit to identify individuals who are at low risk of developing severe, complicated alcohol withdrawal and thus do not require inpatient admission or benzodiazepine therapy for symptom management [62].

Psychosocial interventions for alcohol misuse among OAT participants have previously been described [50, 51, 53]. More specifically, clinician delivered brief intervention was shown to reduce alcohol consumption among OAT participants without alcohol use disorders (AUDIT score $<20$ ). Such a treatment approach is recommended for all alcohol misusers identified through screening by the European clinical guidelines previously described [59]. Furthermore a pilot study and randomized controlled trial have identified motivational interviewing to be an effective strategy to reduce alcohol consumption among alcohol misusing methadone maintained participants $[51,53]$. Though not specific to OAT participants, psychosocial interventions for alcohol misuse among concurrent substance users have been described in a systematic review [52]. Four studies involving 594 participants evaluated 6 psychosocial interventions through 4 comparison groups: cognitive-behavioral coping skills training versus 12-step facilitation $(\mathrm{n}=41)$ [63], brief intervention versus treatment as usual $(n=110)$ [64], hepatitis health promotion versus motivational interviewing $(\mathrm{n}=256)$ [51] and brief motivational intervention versus assessment only group $(n=187)$ [65]. Higher rates of decreased alcohol use were found at 3 and 9 months among the treatment as usual group when compared to brief intervention [64] and more people reduced their alcohol use at 6 months (by 7 or more days in the preceding 30 days) in the brief motivational intervention group compared to control [65]. No other comparisons were found to be statistically significant and because of methodological study differences, no meta-analysis could be performed. Overall the authors were unable to recommend for or against the use of psychosocial interventions for alcohol misuse among concurrent substance users, which is similar to previous findings $[66,67]$.

While the effectiveness of medications for alcohol relapse prevention including naltrexone and acamprosate has been described among the general population [68, 69], opioid antagonist use among those on OAT is not possible given the effects of naltrexone on OAT and the emergence of precipitated withdrawal. In terms of acamprosate, no studies to date have been conducted among 
OAT participants who misuse alcohol. The use of disulfiram for reducing heavy alcohol consumption among patients receiving methadone maintenance therapy was evaluated in one randomized double-blind controlled trial [70] with the results showing no significant difference compared to placebo (though the trial was stopped early when sample size targets were not achieved). While two subsequent meta-analyses [71, 72] did demonstrate efficacy with the use of disulfiram when administered in a supervised setting among individuals with alcohol abuse or dependence regarding short term abstinence, days until relapse and number of drinking days, it should be noted that receipt of methadone was an exclusion criteria in one of these studies [71] with the other [72] including only 2 small randomized controlled trials of methadone maintenance patients. Given these findings, there is an urgent need to evaluate the use of such medications, or others used off label for the treatment of alcohol addiction (e.g. gabapentin) [73-75] specifically among OAT participants, as their administration in this setting is a feasible strategy.

Another promising option for this treatment population is extended release naltrexone. Here, while oral naltrexone has not been shown to be superior to placebo in the context of opioid dependence, studies of extended release naltrexone (XR-NTX) have shown promise for the treatment of both alcohol misuse and opioid dependence [76-78]. Prior to initiation with this opioid antagonist, patients are required to have completed opioid detoxification and not be receiving any ongoing opioids (including either methadone or buprenorphine). In settings where XR-NTX is available, this would be an option and its rigorous evaluation in the context of alcohol and opioid poly-substance addiction is warranted.

\section{Conclusions}

Alcohol misuse is common among OAT participants and is associated with a number of adverse outcomes including overdose and mortality. Despite this, the literature suggests that screening and treatment for alcohol misuse among this patient population consistently goes overlooked. To overcome these challenges, future research should focus on the development of strategies to increase rates and frequency of alcohol screening and brief intervention among OAT providers. Guidance for effective alcohol detoxification strategies and an evaluation of acamprosate's and XR-NTX's effectiveness for relapse prevention among this patient population is also of importance. Lastly, eliminating barriers for accessing alcohol addiction treatment programs for individuals on $\mathrm{OAT}$ is essential as is the integration of alcohol misuse treatment into OAT primary care settings.
Authors' contributions

SN and EW designed and prepared the first draft of the manuscript. All COauthors contributed to drafting the final manuscript. All authors read and approved the final manuscript.

\section{Author details}

${ }^{1}$ British Columbia Centre for Excellence in HIV/AIDS, St. Paul's Hospital, 608-1081 Burrard Street, Vancouver, BC V6Z 1Y6, Canada. ${ }^{2}$ Department of Medicine, University of British Columbia, St. Paul's Hospital, 608-1081 Burrard Street, Vancouver, BC V6Z 1Y6, Canada. ${ }^{3}$ School of Medicine and Medical Science, University College Dublin, Coombe Healthcare Centre, Dolphins Barn, Dublin, Ireland.

\section{Acknowledgements}

Not applicable.

\section{Competing interests}

The authors declare that they have no competing interests.

\section{Funding}

JK is supported by The ELEVATE Grant: Irish Research Council International Career Development Fellowship_co-funded by Marie Cure Actions (ELEVATEPD/2014/6); and the European Commission Grant (701698). EW is supported by funding from the Canada Research Chairs program through a Tier 1 Canada Research Chair in Inner City Medicine.

Received: 11 July 2016 Accepted: 29 November 2016

Published online: 08 December 2016

\section{References}

1. Soyka M. Alcohol use disorders in opioid maintenance therapy: prevalence, clinical correlates and treatment. Eur Addict Res. 2015;21 (2):78-87.

2. Degenhardt L, Hall W. Patterns of co-morbidity between alcohol use and other substance use in the Australian population. Drug Alcohol Rev. 2003;22(1):7-13.

3. Potter JS, Marino EN, Hillhouse MP, Nielsen S, Wiest K, Canamar CP, et al. Buprenorphine/naloxone and methadone maintenance treatment outcomes for opioid analgesic, heroin, and combined users: findings from starting treatment with agonist replacement therapies (START). J Stud Alcohol Drugs. 2013;74(4):605-13.

4. Rowan-Szal GA, Chatham LR, Simpson DD. Importance of identifying cocaine and alcohol dependent methadone clients. Am J Addict. 2000;9(1):38-50.

5. Gossop M, Marsden J, Stewart D, Rolfe A. Patterns of drinking and drinking outcomes among drug misusers. 1-Year follow-up results. J Subst Abuse Treat. 2000;19(1):45-50.

6. el-Bassel N, Schilling RF, Turnbull JE, Su KH. Correlates of alcohol use among methadone patients. Alcohol Clin Exp Res. 1993;17(3):681-6.

7. Klimas J, Marie Henihan A, McCombe G, Swan D, Anderson R, Bury G, et al. Psychosocial interventions for problem alcohol use in primary care settings (PINTA): baseline feasibility data. J Dual Diagn. 2015;1 1(2):97-106.

8. Aharonovich E, Nguyen HT, Nunes EV. Anger and depressive states among treatment-seeking drug abusers: testing the psychopharmacological specificity hypothesis. Am J Addict. 2001;10(4):327-34.

9. Hartzler B, Donovan DM, Huang Z. Comparison of opiate-primary treatment seekers with and without alcohol use disorder. J Subst Abuse Treat. 2010;39(2):114-23.

10. Lloyd JJ, Ricketts EP, Havens JR, Cornelius LJ, Bishai D, Huettner S, et al. The relationship between lifetime abuse and suicidal ideation in a sample of injection drug users. J Psychoactive Drugs. 2007;39(2):159-66.

11. Ostapowicz G, Watson KJ, Locarnini SA, Desmond PV. Role of alcohol in the progression of liver disease caused by hepatitis $C$ virus infection. Hepatology. 1998;27(6):1730-5.

12. Oyefeso A, Brown S, Chiang Y, Clancy C. Self-injurious behaviour, traumatic life events and alexithymia among treatment-seeking opiate addicts: prevalence, pattern and correlates. Drug Alcohol Depend. 2008;98(3):227-34. 
13. Rodger AJ, Roberts S, Lanigan A, Bowden S, Brown T, Crofts N. Assessment of long-term outcomes of community-acquired hepatitis $C$ infection in a cohort with sera stored from 1971 to 1975. Hepatology. 2000;32(3):582-7.

14. Senbanjo R, Wolff K, Marshall J. Excessive alcohol consumption is associated with reduced quality of life among methadone patients. Addiction. 2007;102(2):257-63.

15. Sendi P, Hoffmann M, Bucher HC, Erb P, Haller P, Gyr N, et al. Intravenous opiate maintenance in a cohort of injecting drug addicts. Drug Alcohol Depend. 2003;69(2):183-8.

16. National Institute on Alcohol Abuse and Alcoholism. Drinking levels defined. https://www.niaaa.nih.gov/alcohol-health/overview-alcoholconsumption/moderate-binge-drinking. Accessed 29 June 2016.

17. Ryder N, Cullen W, Barry J, Bury G, Keenan E, Smyth BP. Prevalence of problem alcohol use among patients attending primary care for methadone treatment. BMC Fam Pract. 2009;10:42.

18. Oswald LM, Wand GS. Opioids and alcoholism. Physiol Behav. 2004;81(2):339-58.

19. Clark NC, Dietze P, Lenne MG, Redman JR. Effect of opioid substitution therapy on alcohol metabolism. J Subst Abuse Treat. 2006;30(3):191-6.

20. Donnelly B, Balkon J, Lasher C, Lynch V, Bidanset JH, Bianco J. Evaluation of the methadone-alcohol interaction. I. Alterations of plasma concentration kinetics. J Anal Toxicol. 1983;7(5):246-8.

21. Tommasello AC, Adir J. Alcohol and the steady-state disposition kinetics of methadone in rats. J Stud Alcohol. 1984;45(2):155-9.

22. Borowsky SA, Lieber CS. Interaction of methadone and ethanol metabolism. J Pharmacol Exp Ther. 1978;207(1):123-9.

23. Kreek MJ. Metabolic interactions between opiates and alcohol. Ann NY Acad Sci. 1981;362:36-49.

24. Wendell GD, Thurman RG. Effect of ethanol concentration on rates of ethanol elimination in normal rats in vivo. Curr Alcohol. 1979;5:81-9.

25. Umans HR, Kreek MJ, Rodriguez R, Raghunath J. Effects of chronic methadone treatment on the rate of ethanol elimination in the female rat in vivo. Am Gastroenterol Assoc. 1982;82:1247.

26. Kreek MJ. Opioid interactions with alcohol. Adv Alcohol Subst Abuse. 1984;3(4):35-46.

27. Lenne MG, Dietze P, Rumbold GR, Redman JR, Triggs TJ. The effects of the opioid pharmacotherapies methadone, LAAM and buprenorphine, alone and in combination with alcohol, on simulated driving. Drug Alcohol Depend. 2003;72(3):271-8.

28. Caputo F, Addolorato G, Domenicali M, Mosti A, Viaggi M, Trevisani F, et al. Short-term methadone administration reduces alcohol consumption in non-alcoholic heroin addicts. Alcohol Alcohol. 2002;37(2):164-8.

29. Hser YI, Anglin MD, Powers K. Longitudinal patterns of alcohol use by narcotics addicts. Recent Dev Alcohol. 1990;8:145-71.

30. Anglin MD, Almog IJ, Fisher DG, Peters KR. Alcohol use by heroin addicts: evidence for an inverse relationship. A study of methadone maintenance and drug-free treatment samples. Am J Drug Alcohol Abuse. 1989:15(2):191-207.

31. Klimas J, Wood E, Nguyen P, Dong H, Milloy MJ, Kerr T, et al. The impact of enrolment in methadone maintenance therapy on initiation of heavy drinking among people who use heroin. Eur Addict Res. 2016;22(4):210-4.

32. Nava F, Manzato E, Leonardi C, Lucchini A. Opioid maintenance therapy suppresses alcohol intake in heroin addicts with alcohol dependence: preliminary results of an open randomized study. Prog Neuropsychopharmacol Biol Psychiatry. 2008;32(8):1867-72.

33. Srivastava A, Kahan M, Ross S. The effect of methadone maintenance treatment on alcohol consumption: a systematic review. J Subst Abuse Treat. 2008:34(2):215-23.

34. Zador D, Sunjic $S$. Deaths in methadone maintenance treatment in New South Wales, Australia 1990-1995. Addiction. 2000;95(1):77-84.

35. Joseph $\mathrm{H}, \mathrm{Appel}$ P. Alcoholism and methadone treatment: consequences for the patient and program. Am J Drug Alcohol Abuse. 1985;11(1-2):37-53.

36. Caplehorn JR, Drummer OH. Mortality associated with New South Wales methadone programs in 1994: lives lost and saved. Med J Aust. 1999;170(3):104-9.

37. Webster LR, Cochella S, Dasgupta N, Fakata KL, Fine PG, Fishman SM, et al. An analysis of the root causes for opioid-related overdose deaths in the United States. Pain Med. 2011;12(Suppl 2):S26-35.
38. Hakkinen M, Launiainen T, Vuori E, Ojanpera I. Comparison of fatal poisonings by prescription opioids. Forensic Sci Int. 2012;222(1-3):327-31.

39. Abraham HD, Degli-Esposti S, Marino L. Seroprevalence of hepatitis $C$ in a sample of middle class substance abusers. J Addict Dis. 1999;18(4):77-87.

40. DiazT, Des Jarlais DC, Vlahov D, Perlis TE, Edwards V, Friedman SR, et al. Factors associated with prevalent hepatitis $C$ : differences among young adult injection drug users in lower and upper Manhattan, New York City. Am J Public Health. 2001;91(1):23-30.

41. Murrill CS, Weeks H, Castrucci BC, Weinstock HS, Bell BP, Spruill C, et al. Age-specific seroprevalence of HIV, hepatitis B virus, and hepatitis C virus infection among injection drug users admitted to drug treatment in 6 US cities. Am J Public Health. 2002;92(3):385-7.

42. Novick DM, Kreek MJ. Critical issues in the treatment of hepatitis $C$ virus infection in methadone maintenance patients. Addiction. 2008;103(6):905-18.

43. Patrick DM, Tyndall MW, Cornelisse PG, Li K, Sherlock CH, Rekart ML, et al. Incidence of hepatitis $C$ virus infection among injection drug users during an outbreak of HIV infection. CMAJ. 2001;165(7):889-95.

44. Rosenblum A, Nuttbrock L, McQuistion HL, Magura S, Joseph H. Hepatitis C and substance use in a sample of homeless people in New York City. J Addict Dis. 2001;20(4):15-25.

45. Westreich LM. Alcohol and mental illness: clinical focus. Primary Psychiatry. 2005;12(1):41-6.

46. Moussas G, Fanouraki I, Pachi A, Asomatou A, Drylli O, Paschalakis G, et al. Comorbid psychopathology and alcohol use patterns among methadone maintenance treatment patients. J Addict. 2015;2015:197652.

47. Roy-Byrne P, Bumgardner K, Krupski A, Dunn C, Ries R, Donovan D, et al. Brief intervention for problem drug use in safety-net primary care settings: a randomized clinical trial. JAMA. 2014;312(5):492-501.

48. Saitz R, Palfai TP, Cheng DM, Alford DP, Bernstein JA, Lloyd-Travaglini CA, et al. Screening and brief intervention for drug use in primary care: the ASPIRE randomized clinical trial. JAMA. 2014;312(5):502-13.

49. McQueen J, Howe TE, Allan L, Mains D, Hardy V. Brief interventions for heavy alcohol users admitted to general hospital wards. Cochrane Database Syst Rev. 2011;8:Cd005191.

50. Darker CD, Sweeney BP, El Hassan HO, Smyth BP, Ivers JH, Barry JM. Brief interventions are effective in reducing alcohol consumption in opiatedependent methadone-maintained patients: results from an implementation study. Drug Alcohol Rev. 2012;31(3):348-56.

51. Nyamathi A, Shoptaw S, Cohen A, Greengold B, Nyamathi K, Marfisee $M$, et al. Effect of motivational interviewing on reduction of alcohol use. Drug Alcohol Depend. 2010;107(1):23-30.

52. Klimas J, Tobin H, Field CA, O'Gorman CS, Glynn LG, Keenan E, et al. Psychosocial interventions to reduce alcohol consumption in concurrent problem alcohol and illicit drug users. Cochrane Database Syst Rev. 2014;12:Cd009269.

53. Bennett GA, Edwards S, Bailey J. Helping methadone patients who drink excessively to drink less: short-term outcomes of a pilot motivational intervention. J Subst Use. 2002;7(4):191-7.

54. Darker CD, Sweeney B, Keenan E, Whiston L, Anderson R, Barry J. Screening and brief interventions for illicit drug use and alcohol use in methadone maintained opiate-dependent patients: results of a pilot cluster randomized controlled feasibility study. Subst Use Misuse. 2016;51(9):1104-15

55. Field CA, Klimas J, Barry J, Bury G, Keenan E, Smyth BP, et al. Problem alcohol use among problem drug users in primary care: a qualitative study of what patients think about screening and treatment. BMC Fam Pract. 2013;14:98.

56. Williams EC, Johnson ML, Lapham GT, Caldeiro RM, Chew L, Fletcher GS, et al. Strategies to implement alcohol screening and brief intervention in primary care settings: a structured literature review. Psychol Addict Behav. 2011;25(2):206-14.

57. Anderson P, Laurant M, Kaner E, Wensing M, Grol R. Engaging general practitioners in the management of hazardous and harmful alcohol consumption: results of a meta-analysis. J Stud Alcohol. 2004:65(2):191-9.

58. Field CA, Klimas J, Barry J, Bury G, Keenan E, Lyons S, et al. Attitudes and practices regarding the management of problem alcohol use among patients receiving opiate substitution treatment in primary care in Ireland: a cross sectional survey of GPS. Paper presented at the annual symposium of the society for the study of addiction, York, UK; 2013. 
59. Klimas J, Cullen W, Field CA. Problem alcohol use among problem drug users: development and content of clinical guidelines for general practice. Ir J Med Sci. 2014;183(1):89-101.

60. National Institute on Alcohol Abuse and Alcoholism. Methadone maintenance and patients in alcoholism treatment. Alcohol Alert. No. 1, 1988. http://pubs.niaaa.nih.gov/publications/aa01.htm. Accessed 29 June 2016

61. Kapur BM, Hutson JR, Chibber T, Luk A, Selby P. Methadone: a review of drug-drug and pathophysiological interactions. Crit Rev Clin Lab Sci. 2011;48(4):171-95.

62. Maldonado JR, Sher Y, Das S, Hills-Evans K, Frenklach A, Lolak S, et al. Prospective validation study of the prediction of alcohol withdrawal severity scale (PAWSS) in medically ill inpatients: a new scale for the prediction of complicated alcohol withdrawal syndrome. Alcohol Alcohol. 2015;50(5):509-18.

63. Carroll KM, Nich C, Ball SA, McCance E, Rounsavile BJ. Treatment of cocaine and alcohol dependence with psychotherapy and disulfiram. Addiction. 1998;93(5):713-27.

64. Feldman N, Chatton A, Khan R, Khazaal Y, Zullino D. Alcohol-related brief intervention in patients treated for opiate or cocaine dependence: a randomized controlled study. Subst Abuse Treat Prev Policy. 2011;6:22.

65. Stein MD, Charuvastra A, Maksad J, Anderson BJ. A randomized trial of a brief alcohol intervention for needle exchangers (BRAINE). Addiction. 2002;97(6):691-700

66. Arias AJ, Kranzler HR. Treatment of co-occurring alcohol and other drug use disorders. Alcohol Res Health. 2008;31(2):155-67.

67. Bickel WK, Marion I, Lowinson JH. The treatment of alcoholic methadone patients: a review. J Subst Abuse Treat. 1987;4(1):15-9.

68. Rosner S, Hackl-Herrwerth A, Leucht S, Vecchi S, Srisurapanont M, Soyka M. Opioid antagonists for alcohol dependence. Cochrane Database Syst Rev. 2010;12:67

69. Rosner S, Hackl-Herrwerth A, Leucht S, Lehert P, Vecchi S, Soyka M. Acamprosate for alcohol dependence. Cochrane Database Syst Rev. 2010;9:332.
70. Ling W, Weiss DG, Charuvastra VC, O'Brien CP. Use of disulfiram for alcoholics in methadone maintenance programs. A Veterans Administration Cooperative Study. Arch Gen Psychiatry. 1983;40(8):851-4.

71. Jorgensen $\mathrm{CH}$, Pedersen $\mathrm{B}$, Tonnesen $\mathrm{H}$. The efficacy of disulfiram for the treatment of alcohol use disorder. Alcohol Clin Exp Res. 2011;35(10):1749-58

72. Skinner MD, Lahmek $\mathrm{P}$, Pham H, Aubin HJ. Disulfiram efficacy in the treatment of alcohol dependence: a meta-analysis. PLoS ONE. 2014;9(2):e87366.

73. Leung JG, Hall-Flavin D, Nelson S, Schmidt KA, Schak KM. The role of gabapentin in the management of alcohol withdrawal and dependence. Ann Pharmacother. 2015;49(8):897-906.

74. Myrick H, Malcolm R, Randall PK, Boyle E, Anton RF, Becker HC, et al. A double-blind trial of gabapentin versus lorazepam in the treatment of alcohol withdrawal. Alcohol Clin Exp Res. 2009;33(9):1582-8.

75. Stock CJ, Carpenter L, Ying J, Greene T. Gabapentin versus chlordiazepoxide for outpatient alcohol detoxification treatment. Ann Pharmacother. 2013:47(7-8):961-9.

76. Garbutt JC, Kranzler HR, O'Malley SS, Gastfriend DR, Pettinati HM, Silverman BL, et al. Efficacy and tolerability of long-acting injectable naltrexone for alcohol dependence: a randomized controlled trial. JAMA. 2005;293(13):1617-25.

77. Comer SD, Sullivan MA, Yu E, Rothenberg JL, Kleber HD, Kampman K, et al. Injectable, sustained-release naltrexone for the treatment of opioid dependence: a randomized, placebo-controlled trial. Arch Gen Psychiatry. 2006;63(2):210-8

78. Krupitsky E, Nunes EV, Ling W, Illeperuma A, Gastfriend DR, Silverman $B L$. Injectable extended-release naltrexone for opioid dependence: a double-blind, placebo-controlled, multicentre randomised trial. Lancet. 2011;377(9776):1506-13.

\section{Submit your next manuscript to BioMed Central and we will help you at every step:}

- We accept pre-submission inquiries

- Our selector tool helps you to find the most relevant journal

- We provide round the clock customer support

- Convenient online submission

- Thorough peer review

- Inclusion in PubMed and all major indexing services

- Maximum visibility for your research

Submit your manuscript at www.biomedcentral com/submit 